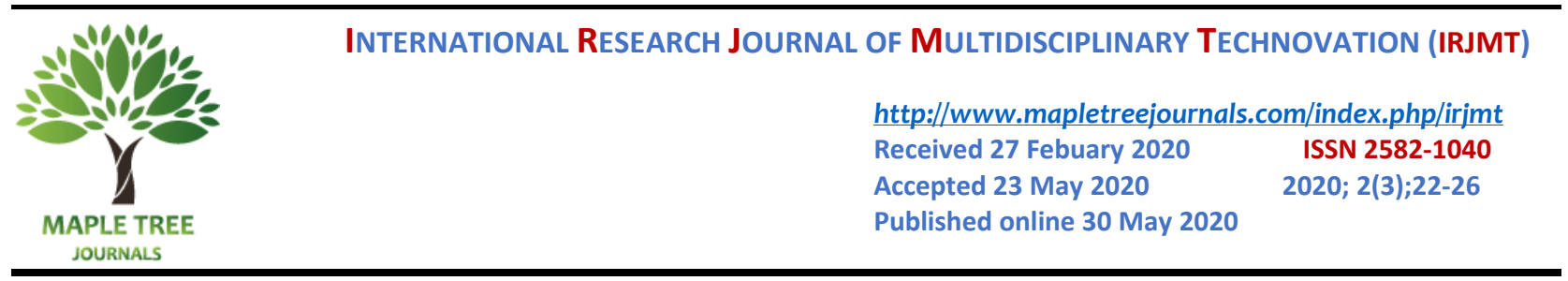

\title{
Best Mix Ratio for Concrete Printing using Localised Materials
}

\author{
Priyadharshini M ${ }^{1, *}$, S. Sam Chelladurai ${ }^{2}$ \\ ${ }^{1}$ Department of Structural Engineering, CSI College of Engineering, Ketti, Ooty-643215, Tamil Nadu, India \\ ${ }^{2}$ Department of Mechanical Engineering, CSI College of Engineering, Ketti, Ooty-643215, Tamil Nadu, India \\ *Corresponding author E-Mail ID: peiyashaket@gmail.com
}

DOI: https://doi.org/10.34256/irjmt2034

\begin{abstract}
A method is proposed for assessing best mix ratio for concrete printing. The obtained mix which is indented to flow via a nozzle for building a layer upon layer construction structures. The printing method consists of a gantry system which can be controlled with the help of a digital computer. This method is nowadays used for building structural and architectural components. Thus the traditional form work is avoided. Buildability and Extrudability are some of the important flow concrete properties That have to be considered and the relationship with Workability is evaluated. This property depends on the mix ratio and the quantity of admixtures like superplasticizer, polypropylene fibers and silica fume. Hydrated sodium silicate is also added for quick settlement which is essential for the layer by layer process.
\end{abstract}

Keywords: Contour crafting, Additive manufacturing, Layered Manufacturing, Adhesion.

\section{Introduction}

Concrete printing has proved to be a new breakthrough in the field of construction [1]. This type of printing is similar to the technology used in the Additive Manufacturing. Just as plastic is used to print an object layer by layer in Additive Manufacturing, concrete is mixed and poured layer by layer and concrete structures are built [2]. This type of construction is also known as free form construction. The concrete printing can be used to meet variety of needs [3].

In the process of concrete printing, first a 3D modelling software is used where the model of a building to be built is designed [4]. Then, the designed model is uploaded in the next software, which is the slicing software. The slicing software then slices the 3D design into 2 dimensional layers [5]. As the next step, the sliced 2 dimensional layers are fed into the printing machine [6]. The machine gives instruction to the nozzle to print the layers according to its contour, and the nozzle deposits the concrete as per the instruction to get a complete structure [7].

As there is the usage of software and printing, the concrete printing can be used to build complex structures [8]. The proposed structure need not be a straight wall or a square or rectangular room [9]. The structure can be curved, crooked, spherical or even pyramids. Potential advantages including constructing a structure without later damaging the structure for inclusion of plumbing, electrical wiring, AC duct fixing, etc. The provision for the above work can be given as and when the printing takes place. Another salient feature of this printing is the finishing which will be excellent compared to the conventional method [10]. No plastering of the constructed structure is required [11]. 
This concrete printing is an improvisation in the field of construction [12]. When the concrete is extruded through the nozzle, the filament helps in proper binding of the newly printed layer with the previously printed layer [13]. Thus, with the addition of every new layer, the building progresses an entire structure is formed without any difficulty [14].

This concrete printing is also called as concrete crafting as more crafting is involved than building [15]. Spraying method of concrete through a nozzle is also used to attain perfection [16].

To make this method more effective, we can make use of the materials available locally to make the concrete mixture. Materials like cement, soil, fly ash, mica polypropylene, and water can be got from the local area and an appropriate mixture with proper ratio can be made [17]. The types of materials used and its ratio is discussed in this paper.

\section{Optimum mix proportions}

\subsection{Goal}

To identify optimum mix proportions, nine trial mixes were designed for the use of concrete printing. The best suited method for printing freeform components according to the extrudability tests showed Mix 6 in which water to binder is a proportion ratio of 0.26 . and this has a sand to binder ratio of 60:40 ratio which comprises of $70 \%$ of cement, $20 \%$ of fly ash and $10 \%$ of silica fume. Added to this, 1.2 Kilos per meter cube of polypropylene fibres are included in the above mixture. The optimum workability of $0.55 \mathrm{kPa}$ shear strength, the mix also needed $1 \%$ superplasticizer and $0.5 \%$ retarder. With the above components, an optimim open time of up to 100 minutes can be attained and it also creates an capacity to fabricate multiple layers. The specimens are further casted to determine the compressive strength and the same was found to be 9.7MPa that was measured at 756 days with BS EN12390-2:2009 s[20].

\subsection{Fabricating Realtime Structure}

The Concrete properties were evaluated using the laboratory tests. The results which show that the concrete properties that are essential to print the developed concrete with the hardware. But to demonstrate as per the designed mix design followed by evaluation, fabrication of the realtime structures were essential. A realtime component that can be used as a prefabricated wall is printed.

As illustrated in the below Fig.1, before printing layer-by-layer a 3D model, the orthogonal array has been designed. The measurement of the printed component was about $2 \mathrm{~m}$ long, a maximum width of $0.9 \mathrm{~m}$ and a height of $0.8 \mathrm{~m}$ which is comprised of 128 layers of $6 \mathrm{~mm}$ thickness.

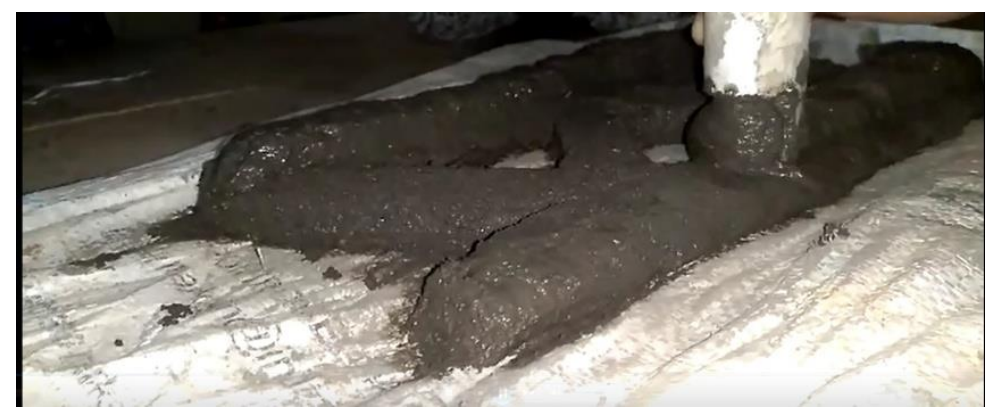

Fig 1. Printing layer-by-layer 


\section{Experiment and Result}

The set of experiment comprises of mix design followed by the study of the mix proportions with the admixtures [18] and evaluate the printability large-scale freeform component is evaluated and documented.

Table 1. Experiment and Result

\begin{tabular}{|l|l|l|l|l|l|l|}
\hline S.NO & EXPERIMENT & CEMENT & SAND & CLAY & $\begin{array}{l}\text { SUPER PLASTIZER RESULT } \\
\text { SILICA FUME+ } \\
\text { POLYPROPYLENE }\end{array}$ & ( \\
\hline 1 & TRIAL-1 & $0.9 \mathrm{Kg}$ & $3.5 \mathrm{Kg}$ & $0.75 \mathrm{Kg}$ & $400 \mathrm{~g}+40 \mathrm{ml}+$ Less & $9 \mathrm{~N} / \mathrm{mm}^{2}$ \\
\hline 2 & TRIAL-2 & $0.9 \mathrm{Kg}$ & $4 \mathrm{Kg}$ & $1 \mathrm{Kg}$ & $500 \mathrm{~g}+50 \mathrm{ml}+$ Medium & $8.3 \mathrm{~N} / \mathrm{mm}^{2}$ \\
\hline 3 & TRIAL-3 & $0.9 \mathrm{Kg}$ & $4.5 \mathrm{Kg}$ & $1.25 \mathrm{Kg}$ & $600 \mathrm{~g}+60 \mathrm{ml}+$ More & $7 \mathrm{~N} / \mathrm{mm}^{2}$ \\
\hline 4 & TRIAL-4 & $1 \mathrm{Kg}$ & $3.5 \mathrm{Kg}$ & $1 \mathrm{Kg}$ & $600 \mathrm{~g}+60 \mathrm{ml}+$ More & $9 \mathrm{~N} / \mathrm{mm}^{2}$ \\
\hline 5 & TRIAL-5 & $1 \mathrm{Kg}$ & $4 \mathrm{Kg}$ & $1.25 \mathrm{Kg}$ & $400 \mathrm{~g}+40 \mathrm{ml}+$ Less & $9.5 \mathrm{~N} / \mathrm{mm}^{2}$ \\
\hline 6 & TRIAL-6 & $1 \mathrm{Kg}$ & $4.5 \mathrm{Kg}$ & $0.75 \mathrm{Kg}$ & $500 \mathrm{~g}+50 \mathrm{ml}+$ Medium & $9.7 \mathrm{~N} / \mathrm{mm}^{2}$ \\
\hline 7 & TRIAL-7 & $1.1 \mathrm{Kg}$ & $3.5 \mathrm{Kg}$ & $1.25 \mathrm{Kg}$ & $500 \mathrm{~g}+50 \mathrm{ml}+$ Medium & $8.5 \mathrm{~N} / \mathrm{mm}^{2}$ \\
\hline 8 & TRIAL-8 & $1.1 \mathrm{Kg}$ & $4 \mathrm{Kg}$ & $0.75 \mathrm{Kg}$ & $600 \mathrm{~g}+60 \mathrm{ml}+$ More & $7.5 \mathrm{~N} / \mathrm{mm}^{2}$ \\
\hline 9 & TRIAL-9 & $1.1 \mathrm{Kg}$ & $4.5 \mathrm{Kg}$ & $1 \mathrm{Kg}$ & $400 \mathrm{~g}+40 \mathrm{ml}+$ Less & $7.5 \mathrm{~N} / \mathrm{mm}^{2}$ \\
\hline
\end{tabular}

The above table shows the experimental analysis [19] which is finally proven that the best mix for printing concrete is Trial 6 from the orthogonal array analysis. This experiment gives the better strength of $9.7 \mathrm{~N} / \mathbf{m m}^{2}$ within a short span of 7 days.

\section{Conclusion}

For an innovative printing process, a novel flow able concrete is synthesized. With the use of architectural and structural components, a freeform fabrication method controlled by a digital compoter is undertaken without formwork which is different from conventional concrete methods. Extrudability and buildability are the critical fresh properties of the above developed concrete which also has equal effect on workability and open time. Based on the studied theories, it is shown that it also helps in providing good performance of the mix design. The experimental analysis shows that for printing concrete using orthogonal array analysis, the best mix would be Trial 6 mixture wherein Cement, Sand and (Clay+Silica fume) in the ratio of 1:2.1:4 which gives the better strength of $9.7 \mathrm{~N} / \mathrm{mm}^{2}$ within 7 days. To validate the realtime structures were also fabricated and tested.

\section{References}

[1] H. Okamura, \& M. Ouchi, Self-compacting concrete, Journal of advanced concrete technology, 1(2003) 5-15.

[2] RILEM Technical Committee, Final report of RILEM TC 188-CSC 'Casting of self compacting concrete', Materials and Structures, 39 (2006) 937-954. 
[3] S.A. Austin, P.J. Robins, \& C.I. Goodier, The rheological performance of wet-process sprayed mortars. Magazine of Concrete Research, 51(1999) 341-352.

[4] S.A. Austin, P. Robins, C.I. Goodier (2002) Construction and Repair with wet-process sprayed SA concrete and mortar, Technical report 56, The concrete society, UK.

[5] R. Buswell, R.C. Soar, A. Gibb, T. Thorpe, Freeform construction: Mega-scale rapid manufacturing for construction, Automation in Construction, 16(2007) 224-231

[6] S. Lim, T. Le, J. Webster, R. Buswell, A. Austin, A. Gibb, \& T. Thorpe, (2009) Fabricating construction components using layered manufacturing technology, In Global Innovation in Construction Conference (pp. 512-520).

[7] S. Jacobsen, L. Haugan, T.A. Hammer, \& E. Kalogiannidis, Flow conditions of fresh mortar and concrete in different pipes. Cement and Concrete Research, 39(2009) 997-1006.

[8] B. Mu, Z. Li, S.N. Chui, \& J. Peng, (1999). Cementitious composite manufactured by extrusion technique, Cement and concrete research, 29(2), 237-240.

[9] Y. Shao, J. Qiu, \& S.P. Shah, Microstructure of extruded cement-bonded fiberboard, Cement and Concrete Research, 31(2001) 1153-1161.

[10] H. Lombois-Burger, P. Colombet, J.L. Halary, \& H. Van Damme, Kneading and extrusion of dense polymer-cement pastes, Cement and concrete research, 36(2006) 2086-2097.

[11] G.H. Tattersall, P.F.G. Banfill, (1983) The rheology of fresh concrete, Pitman Books Ltd., London.

[12] British Standards Institution (1990) BS 1377-9:1990 Methods of test for soils for civil engineering purposes, milton Keynes, UK

[13] R.W. Previte, Concrete slump loss, ACI materials journal, 74 (1977) 361-367

[14] D. Ravina, \& I. Soroka, Slump loss and compressive strength of concrete made with WRR and HRWR admixtures and subjected to prolonged mixing, Cement and concrete research, 24(1994) 1455-1462.

[15] B.G. Kim, S.P. Jiang, P.C. Aitcin, Slump improvement mechanism of alkalies in PNS superplasticized cement pastes, Materials and Structures, 33(2000) 363-369

[16] M.A. Alhozaimy, Effect of absorption of limestone aggregates on strength and slump loss of concrete, Cement and Concrete Composites, 31(2009) 470-473

[17] T. Le, M.N. Soutsos, S.G.Millard, S.J. Barnett, (2007) UHPFRC - Optimisation of mix proportions. Proceedings of concrete platform international conference, Belfast, UK, pp. 339348.

[18] Tarmac Limited (2007) CEMROK 40A - Product information.

[19] British Standards Institution (2009) BS EN 12390-3:2009 Testing hardened concrete, Milton Keynes, UK

\section{Acknowledgement Nil}

\section{Funding}

This study was not funded by any grant

\section{Conflict of interest}

None of the authors have any conflicts of interest to declare. 


\section{About The License}

The text of this article is licensed under a Creative Commons Attribution 4.0 International License

\section{Cite this Article}

Priyadharshini M, S. Sam Chelladurai, Best Mix Ratio for Concrete Printing using Localised Materials, International Research Journal of Multidisciplinary Technovation, Vol 2, Iss 3 (2020) 22-26.

DOI: https://doi.org/10.34256/irimt2033 